University of South Florida

DIGITAL COMMONS

Digital Commons @ University of

@ UNIVERSITY OF SOUTH FLORIDA

South Florida

USF St. Petersburg campus Faculty

Publications

USF Faculty Publications

2018

\title{
Debris, diatoms, and dolphins: tracking child engagement at a public science festival
}

\author{
Kaya van Beynen \\ University of South Florida St. Petersburg, kayatown@usf.edu \\ Theresa G. Burress \\ University of South Florida St. Petersburg, tburress@usf.edu
}

Follow this and additional works at: https://digitalcommons.usf.edu/fac_publications

Part of the Civic and Community Engagement Commons, Library and Information Science Commons, Other Communication Commons, and the Science and Mathematics Education Commons

\section{Recommended Citation}

van Beynen, K., \& Burress, T. (2018). Debris, Diatoms, and Dolphins: Tracking child engagement at a public science festival. International Journal of Science Education, Part B, 355-365. https://doi.org/10.1080/ 21548455.2018.1506189

This Article is brought to you for free and open access by the USF Faculty Publications at Digital Commons @ University of South Florida. It has been accepted for inclusion in USF St. Petersburg campus Faculty Publications by an authorized administrator of Digital Commons @ University of South Florida. For more information, please contact digitalcommons@usf.edu. 
Article Title: Debris, Diatoms, and Dolphins: Tracking Child Engagement at a Public Science Festival International Journal of Science Education, Part B

- $\quad$ https://doi.org/10.1080/21548455.2018.1506189

Authors: Kaya van Beynen and Theresa Burress

Nelson Poynter Memorial Library, University of South Florida St. Petersburg,

\begin{abstract}
Visitors to public science festivals have a tremendous amount of free choice to decide how to navigate through the festival, as well as when, where, and how long to stop at an exhibit. This study examines how elementary-aged children individually or collaboratively engaged with festival exhibits at a public science festival in St. Petersburg, Florida. Although many exhibit activities are designed to appeal to children, no research has been done with regard to child engagement with one-day, outdoor science festivals, such as this one. Engagement can be measured by unobtrusive observation of the behavior and interactions of children. Factors that influenced child engagement in a free-choice learning environment included attention capacity and goals (e.g. engage with exhibits, explore the ambient environment, eat lunch), the ability to interact with peers and adults during their engagement, and the ability to make choices about engaging in collaborative activities or independent free play.
\end{abstract}

Keywords: public science events, informal learning, children, families, engagement, assessment Geolocation information

$27^{\circ} 45^{\prime} 46.8^{\prime \prime} \mathrm{N} 82^{\circ} 38^{\prime} 11.3^{\prime \prime} \mathrm{W}$

$27.762987,-82.636473$

\title{
Funding
}

This work was supported by a mini-methods grant as part of the EvalFest Project, which was in turn funded by National Science Foundation grant \#1423004 . 
Science festivals promote science engagement and learning for a broad public audience. Children and their families are a key science festival constituency and such groups make up the majority of festival attendees. Once they arrive, visitor groups navigate through the festival site, choosing which exhibits to visit, how to engage with activities, and whether to interact with science professionals. Intercept surveys are an established way to measure visitor perceptions and satisfaction with events; however, they are less effective in examining the actual experience of the participants. Unobtrusive observation offers a way to investigate the visitor experience and identify patterns of engagement and interaction in the festival environment.

This study examines how elementary-aged children individually or collaboratively engaged with festival exhibits at a public science festival in St. Petersburg, Florida. Although many exhibit activities are designed to appeal to children, no research has been done with regard to child engagement with oneday, outdoor science festivals, such as this one. Engagement can be measured by observing the behavior and interactions of children. The time children spent actively engaged with the exhibit activities increased when children interacted with either their adult guardians or peers. Some children were highly engaged with the festival's marine setting; others were motivated by festival amenities such as the food trucks. Because families spend valuable leisure time attending these educational events, it is crucial for festival organizers to understand the factors influencing visitor engagement so as to create the optimal conditions in which engagement and learning can occur.

\section{Literature Review}

\section{Science Festivals}

Science festivals have proliferated over the past two decades, due partly to evolving grant criteria that often requires researchers to show evidence of broad dissemination and impact as part of a research project (National Science Foundation, 2018). Science festivals have the purpose of increasing public engagement with science and technology via a two-way communication model, rather than the one-way communication model found in more traditional public science events such as formal lectures (Bultitude, McDonald, \& Custead, 2011). Science festivals often include large-scale, outdoor public expos featuring "street presentations" - exhibit booths designed to engage visitors with hands-on, sciencerelated activities facilitated by science professionals (Jensen \& Buckley, 2014, p. 560). Although science festival exhibits share some common elements with museum exhibits, festival exhibits are often facilitated by a science professional (rather than self-guided or docent-led tours); other differences include a short-term event duration and varied locations (Bultitude, McDonald, \& Custead, 2011; Goodman Research Group, 2013; Jensen \& Buckley, 2014).

\section{Informal Science Learning}

Science learning experiences that take place in informal settings have the potential to improve science education on a national scale (National Research Council, 2009). Informal, or free-choice, ${ }^{1}$ science

\footnotetext{
${ }^{1}$ Free-choice learning is a term coined by John H. Falk (Falk, 2005; Falk et al., 2001) to describe the learning that is typically facilitated by museums, zoos, and more recently, science festivals.
} 
learning has several distinguishing characteristics. Unlike formal science education, which is compulsory, learners are not required to participate (Falk, Donovan, $\&$ Woods, 2001). When they choose to visit an informal science venue, learners typically have some agency in making decisions about their learning goals as well as what constitutes a successful outcome. Informal science education venues design their environments accordingly, with an emphasis on facilitating learning outcomes beyond development of science knowledge, including developing interest in science, engaging in scientific processes and practices, and reflecting on and identifying with the culture of science (National Research Council, 2009). The National Research Council (2009) built upon K-12 science learning outcomes to develop "strands of a science learning framework" that define successful outcomes for science learners in informal settings. Three strands in particular-strand 1 (excitement, curiosity and motivation to learn about science), strand 3 (predict, observe, explore, test, make sense of natural world), and strand 6 (self-identify as science learner or novice scientist) - capture key goals articulated by science festivals.

\section{Evaluation of Festival Engagement}

Evaluating visitor engagement and science learning at science festivals presents challenges, and methods may be adapted from a variety of fields to accommodate varied event locations, duration, and types of exhibits and programming. Research from museum and visitor studies have evaluated the effectiveness of exhibits (Barriault \& Pearson, 2010; Borun, Chambers, Dritsas, \& Johnson, 1997; Falk \& Storksdieck, 2005; Hornecker, 2008), programming (Tal \& Morag, 2007; Wagoner, 2010), and engagement (van Beynen, Pettijohn, \& Carrel, 2010). Factors affecting the visit experience can be the visitors' agenda, interests, and prior knowledge. Other factors that influence the experience are more spatially oriented, such as the exhibit design and overall setting.

Both visitor and space factors need to be considered jointly to fully understand the festival visitor experience and how best to design an environment that encourages and enables engagement, interaction, and learning. Visitors to public spaces unconsciously weigh the perceived or actual costs against the perceived benefits to guide their interaction and movement choices (Bitgood, 2006). These costs may include the time or effort spent to engage in an activity or a negative interaction with another individual, while benefits could be increased knowledge, satisfaction, positive social interaction, and so forth. For example, Borun et al. (1997) and Hornecker (2008) observed visitor engagement with individual exhibits, and recognized that visitor groups communicate with one another during their engagement with self-guided exhibits. Yoon, Lee, \& Lee (2010) established a framework for evaluating festival value based on quality dimensions, including generic festival characteristics, specific program features, information sources, and amenities meant for festival visitors. In addition, they acknowledged that visitor perceptions and satisfaction are influenced by factors related to physical surroundings, which tend to be highly variable at outdoor festivals.

While the intercept survey continues to be a straightforward method widely used for festival evaluation (Durant et al., 2016; Peterman \& Gathings, n.d.; Wilkinson \& Weitkamp, 2016), Seaton (1997) identified multiple limitations of survey instruments during the study of an eight-day music festival in Glasgow. Seaton noted that the brief duration of each event allowed only one opportunity for success, and the survey structure didn't allow for the collection of relevant information on the organizational and experiential aspects of individual events with diverse programs and settings. To compensate for these 
limitations, Seaton implemented an observational program meant to complement the survey data with a reliability cross-check and additional explanatory data.

\section{St. Petersburg Science Festival}

Facilitating active engagement with science has long been a priority for the St. Petersburg Science Festival, whose mission emphasizes informal science learning via hands-on activities for children and adults (St. Petersburg Science Festival, 2011). First established in 2011, the St. Petersburg Science Festival is an annual program held in conjunction with MarineQuest, the open house of the Florida Fish and Wildlife Commission's Fish and Wildlife Research Institute. The week-long festival includes an evening event catering to an adult audience, a Sneak Peek field trip that allows pre-registered groups of $4^{\text {th }}$ and $5^{\text {th }}$ grade students to preview a select group of exhibits, and the capstone public expo featuring a range of programming, including more than 100 exhibit booths, stage shows, concessions, etc.

The public expo is held primarily outdoors on the grounds of the University of South Florida St. Petersburg (USFSP) campus in West-Central Florida. The waterfront campus borders Bayboro Harbor, opening out to Tampa Bay, and consists of a grassy lawn with wide sidewalks, a natural sandy beach, and a sailing marina. It is common to see fish, dolphins, manatees, pelicans, terns, seagulls, and other marine life around the harbor, which complements the festival setting and marine science theme of many exhibit activities.

The intercept survey administered at the 2015 festival included questions designed for child and adult respondents. One hundred percent of child respondents reported "doing an activity" during the 2015 festival, $87.5 \%$ of those children indicated that their "grown-up helped" them do an activity, and $66.7 \%$ of the children "explained an activity" to their accompanying adult (Braunsberger, 2016).

The 2016 public expo featured over 100 exhibits and received an estimated 25,000 visitors (Braunsberger, Jakupaj, Dzien, \& Damian, 2017). The weather was sunny with air temperatures in the mid-70s. According to the 2016 visitor survey, $68.9 \%$ of respondents attended the festival with one or more children age 18 or younger. Visitors were asked the age range of the accompanying children, and $42.7 \%$ of respondents reported having elementary-aged children in their group.

\section{Methodology}

To measure child engagement with science festival exhibits and associated interpersonal interactions, this study utilized unobtrusive observation of children as they navigated through the festival. Trackers randomly selected elementary-aged children accompanied by an adult guardian as they entered the festival, and documented at each exhibit stop how the child engaged with exhibits (waiting, doing, looking), the length of engagement time, and with whom they interacted (scientist exhibitor, adult guardian, or peers) while at the exhibit. The tracking concluded once 25 minutes of tracking had passed or the child left the festival exhibit area.

Seven USFSP undergraduate students worked as trackers for this study. The study instrument was uploaded to an iPad loaded with QuickTab software, which did not require a continuous internet connection during data collection. The trackers received detailed training and an opportunity to practice 
using the instrument and sampling protocol during the Friday school event; the data for this study was collected during the Saturday public expo.

Each exhibit activity was marked with a unique number that was prominently displayed on the exhibit table or tent. A non-specific exhibit number $\varnothing$ was created, and trackers recorded exhibit $\varnothing$ each time a child stopped to interact with the ambient festival environment (e.g., looking at the fish in the water or playing on the beach). On the morning of the festival, the first author verified all exhibit numbers and exhibitor activities at the festival site.

Figure 1. 2016 St. Petersburg Science Festival map showing all exhibit zones.

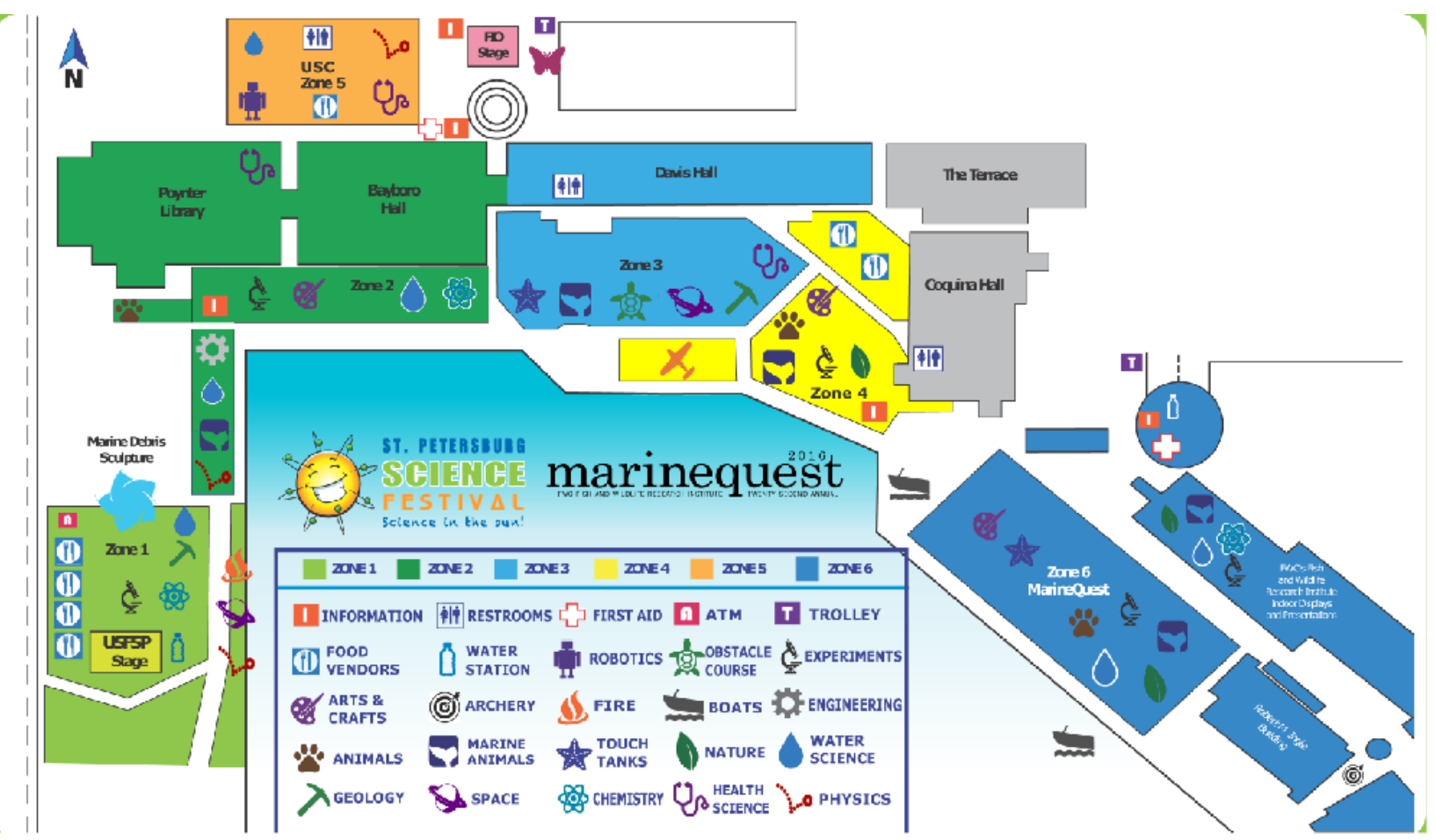

The festival site has five entrances that served as observation starting points (see Figure 1). Each tracker was assigned to an entrance, where they drew an imaginary line and selected the fifth elementary-aged child that crossed that line.

Once a tracker selected a child for observation, s/he began tracking the observation time and discreetly observed the child as $\mathrm{s} /$ he navigated through the festival. A stop was recorded into the instrument only if the child stopped for at least three seconds at an exhibit. At that point, the tracking instrument's internal clock tabulated 1) the amount of time that the child waited, and/or 2) the length of time that the child actively engaged with the exhibit.

The children and families under observation were not contacted during this data collection. Trackers positioned themselves to have a clear line of sight to the subject's activities and interactions, but not close enough to hear conversation. Trackers wore a festival t-shirt to convey a neutral, official appearance and carried a printed information sheet with the study purpose, design, and the first author's mobile phone number to be prepared for questions. The research design called for immediate 
cessation of observation should any family approach a tracker; however, this precaution was not utilized during the study.

The trackers recorded any observed actions that fell within the categories listed in Table 1. At each stop, the trackers noted all applicable engagement and interaction types. Thus, a child could have waited, done an activity, talked to the exhibitor and a peer, all at a single exhibit stop.

Table 1. During each observation, trackers recorded four types of visitor engagement and associated interaction characteristics for each type.

\begin{tabular}{|c|c|c|}
\hline $\begin{array}{l}\text { Engagement } \\
\text { Type }\end{array}$ & Observed Action & Interaction Characteristics \\
\hline Doing & $\begin{array}{l}\text { - Child doing a hands-on activity at an exhibit } \\
\text { (e.g., Making slime, assembling electronic } \\
\text { components, etc.) }\end{array}$ & $\begin{array}{l}\text { - Independently } \\
\text { - In collaboration with adult } \\
\text { guardian } \\
\text { - In collaboration with another child }\end{array}$ \\
\hline Talking & $\begin{array}{l}\text { - Child positioned directly at or in front of } \\
\text { exhibit, and talking or pointing in relation to } \\
\text { the exhibit }\end{array}$ & $\begin{array}{l}\text { - To the exhibitor/scientist } \\
\text { - To adult guardian } \\
\text { - To another child }\end{array}$ \\
\hline Looking & $\begin{array}{l}\text { - Child positioned directly at or in front of } \\
\text { exhibit and appears to be actively reading } \\
\text { or watching } \\
\text { - This could also include performances } \\
\text { (e.g., Mad Science show) }\end{array}$ & $\begin{array}{l}\text { - At the exhibit } \\
\text { - At the exhibitor/scientist }\end{array}$ \\
\hline Waiting & $\begin{array}{l}\text { - Standing in line } \\
\text { - Standing a little removed from exhibit front } \\
\text { or several rows away from the exhibit } \\
\text { table/activity }\end{array}$ & \\
\hline
\end{tabular}

Trackers recorded the number of children and adults in each group. Race and ethnicity were not recorded due to risk of errors. Without this demographic information, the authors have no basis to know whether the children that were tracked were representative of the overall visitor demographics. QuickTab data were downloaded from each iPad to an Excel spreadsheet. Data analysis consisted of descriptive statistics calculated to yield an overall summary of the children's characteristics and pathways through the festival. A Pearson correlation coefficient analysis was calculated for many of the variables (e.g., waiting and engagement times, interaction types) in order to identify any statistically significant positive or negative relationships. Using an Excel template (Flipp, 2017), a cluster analysis of eight variables (engagement time, waiting, doing, looking, exhibitor interaction, adult guardian interaction, peer interaction, and number of stops made) was calculated to identify patterns of child engagement and interaction during the observation. 
This study was generously funded through an EvalFest mini-methods grant. EvalFest is a NSF-funded community of practice, designed to build evaluation capacity within the science festival sector across the United States (www.evalfest.org/). The research methodology was reviewed and deemed exempt by the University of South Florida Institutional Review Board. EvalFest science festival visitor surveys were deemed exempt by the University of North Carolina Institutional Review Board.

\section{Results}

In total, 84 children ( 41 female and 43 male) were observed for up to 25 minutes. These children made 322 unique exhibit stops, and visited an average of six exhibits during their time under observation. 99\% of the children made at least one exhibit stop, $72 \%$ of the children stopped at least at three different exhibits, and $29 \%$ stopped at six different exhibits. The number of exhibit stops ranged from zero - one child walked around for 8 minutes without stopping and left the festival - to 10 exhibits visited by another child in 25 minutes. The observed children visited $78 \%$ of all festival exhibits. Boyd Hill Nature Preserve, an exhibit featuring live predatory birds, received the highest number of visits among the study's sample population with 16 children (19\%) stopping at the exhibit.

Overall, the length of time spent at each stop correlated moderately with the number of exhibit stops the children visited $(r=.57)$. The children spent on average 2.5 minutes engaged in an activity at their first stop; as they moved to subsequent exhibit stops, the children's engagement time steadily increased to over 4 minutes at their fifth stop; at succeeding exhibit stops, engagement time began to decline to an average of 1.5 minutes spent engaged at their seventh stop. The children's engagement time at exhibits ranged from less than 30 seconds (14\%), to 15 minutes spent engaged with a single exhibit. $27 \%$ of the children spent more than 15 of their 25 minutes under observation actively engaged in the exhibits.

During all observed exhibit stops, the children: did the exhibit activity $35 \%$ of the time; talked to an exhibitor $20 \%$; interacted with their guardian (by talking or doing the activity together) $21 \%$ of the time; and/or interacted with another youth (by talking or doing the activity together) $14 \%$ of the time.

\section{Engagement Time and Type}

The more active types of engagement - doing the activity or talking to the exhibitor - occurred during the children's earlier stops. $60 \%$ of the children did an activity in each of their first four stops and $50 \%$ of the children talked to an exhibitor in each of their first six stops. Figure 2 shows that as fewer children moved to additional exhibits, those who continued engaged in fewer types of engagement (e.g., shifting from doing and looking to only looking). Among the children that made more than six stops, they tended to look during exhibit stops 7-10 rather than actively engage in an activity or talk to the exhibitor. Figure 2 displays the proportion of the child engagement type per stop number. However, the children who were actively engaged with an exhibit at their sixth or seventh stop were also simultaneously observed interacting with their adult guardians.

Several children, who were observed with no adult guardian interaction but long engagement time, demonstrated a unique pattern. The data recorded for these children included a stop $\varnothing$, or a non-exhibit 
stop. These children stopped to interact with the waterfront in self-directed activities such as playing on the beach or watching fish in the harbor.

\section{Figure 2: Percent of Child Engagement Type by Exhibit Stop}

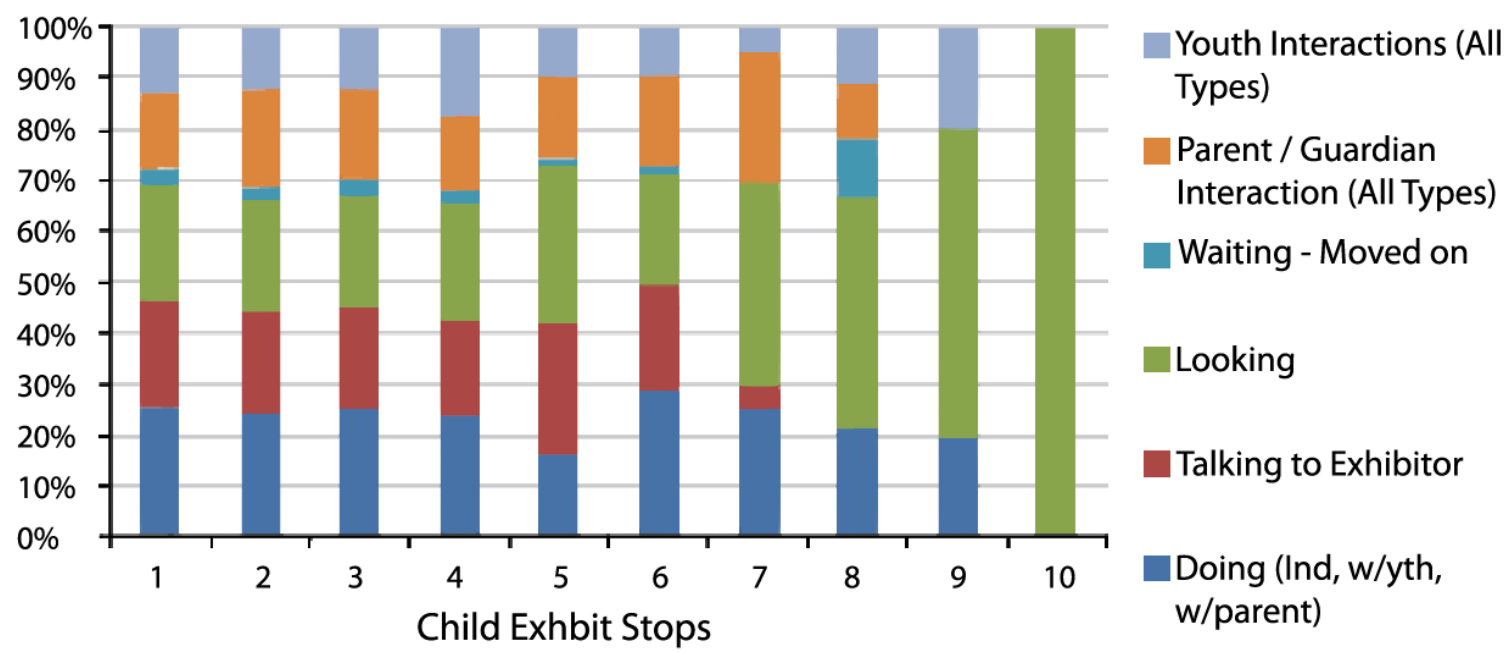

Table 2 shows a strong negative correlation between the number of stops that a child made and whether s/he did an exhibit activity, talked to an exhibitor, or interacted with their adult guardian; and a moderate negative relationship between the number of stops that a child made and their interaction with another youth (i.e., the more exhibits they visited, the more passive their engagement became). Inversely, a strong positive relationship existed between the number of stops a child made and their ever increasing likelihood of just looking. There was no correlation between the number of stops a child made and whether they talked to anyone or waited in line at an exhibit.

In contrast, a strong positive relationship was found between doing an activity, interacting with their adult guardian or looking, while a moderate positive relationship was found between length of engagement time and talking to an exhibitor or interacting with another youth.

Table 2: Statistical Correlation (r): Activity Type, Exhibit Stops, and Average Engagement Time

\begin{tabular}{|r|c|c|}
\hline \multirow{2}{*}{} & \multicolumn{2}{|c|}{ Statistical correlation $(r)$} \\
\cline { 2 - 3 } & Number of stops & $\begin{array}{c}\text { Ave. Time Spent } \\
\text { Engaged }\end{array}$ \\
\hline Doing exhibit activity & $-0.80^{* *}$ & $0.86^{++}$ \\
\hline Talking to Exhibitor & $-0.85^{* *}$ & $0.57^{+}$ \\
\hline Talking (all types) & -0.47 & $0.80^{++}$ \\
\hline Interacting with adult guardian (all types) & $-0.77^{* *}$ & $0.78^{++}$ \\
\hline Interacting with another youth (all types) & $-0.66^{*}$ & $0.65^{+}$ \\
\hline Looking & $0.81^{++}$ & $0.71^{++}$ \\
\hline
\end{tabular}




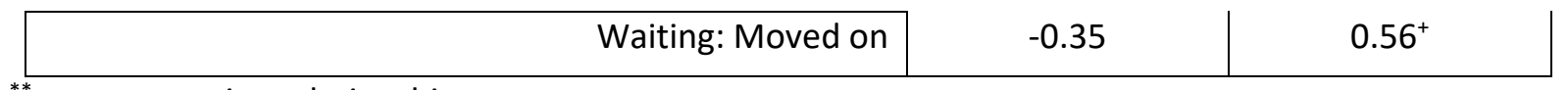

${ }^{* *}$ strong negative relationship

*moderate negative relationship

${ }^{++}$strong positive relationship

${ }^{+}$moderate positive relationship

The tracking concluded after the full 25 minutes of observation (49\%), or when the children left the festival exhibit area to go to MarineQuest (24\%), to the concessions area (12\%), or to leave the festival entirely (15\%).

\section{Waiting}

Overall, the children did not wait long to engage with the exhibit booths and activities. At $87 \%$ of observed stops, the children experienced fewer than 15-second wait times. Most children (95\%) waited at their first stop. Two children waited over 4 minutes at two different exhibits to engage with an activity. Waiting, or not waiting, was not clustered around any particular time of the day. At $2 \%$ of exhibit stops, the children waited briefly but moved on before they engaged with the exhibit. The exhibits that had the highest wait times, in terms of the number of children willing to wait, were the same group of exhibits visited by the highest number of children.

The number of exhibits at which a child waited was not correlated with total time observed $(r=.28)$, time spent engaged in an exhibit $(r=.37)$, or total wait time at an exhibit $(r=.21)$. However, a statistically significant positive relationship was found between the total number of exhibit stops and the number of stops where a child waited $(r=.83)$ : the more stops that a child made, the longer they were willing to wait.

\section{Cluster Analysis}

A cluster analysis of the data revealed that the children displayed four types of engagement patterns (see Figure 3) as they navigated through the festival. Each category was defined as follows:

- Thoughtful observers: $31 \%$ of the children were characterized by high engagement time, waiting time, and looking at the exhibits. They made an average of 5.27 stops. These children infrequently did an exhibit activity and had little interaction with their adult guardian, the exhibitors, or other children.

- Adult Engagers: $18 \%$ of the children were characterized by high rates of interaction with their adult guardian, a high number of exhibit stops, and high rates of doing, waiting, talking to exhibitors, and looking. They had low rates of interacting with other children.

- Peer Engagers: $11 \%$ of the children were characterized by very high rates of interaction with other youth at the exhibit stops, and above average rates of all other time, exhibit stop, engagement, and interaction variables.

- Travelers Passing Through: $40 \%$ of the children were characterized by low levels of all variables. They averaged less than 7 minutes of engagement time, stopped at fewer than two exhibits, and 
did not engage much with exhibits or interact with the exhibitors, adult guardians, or other children. This category included many of the children that went to MarineQuest, the concessions area, or left the festival entirely.

\section{Figure 3: Festival Navigation Patterns by Category}

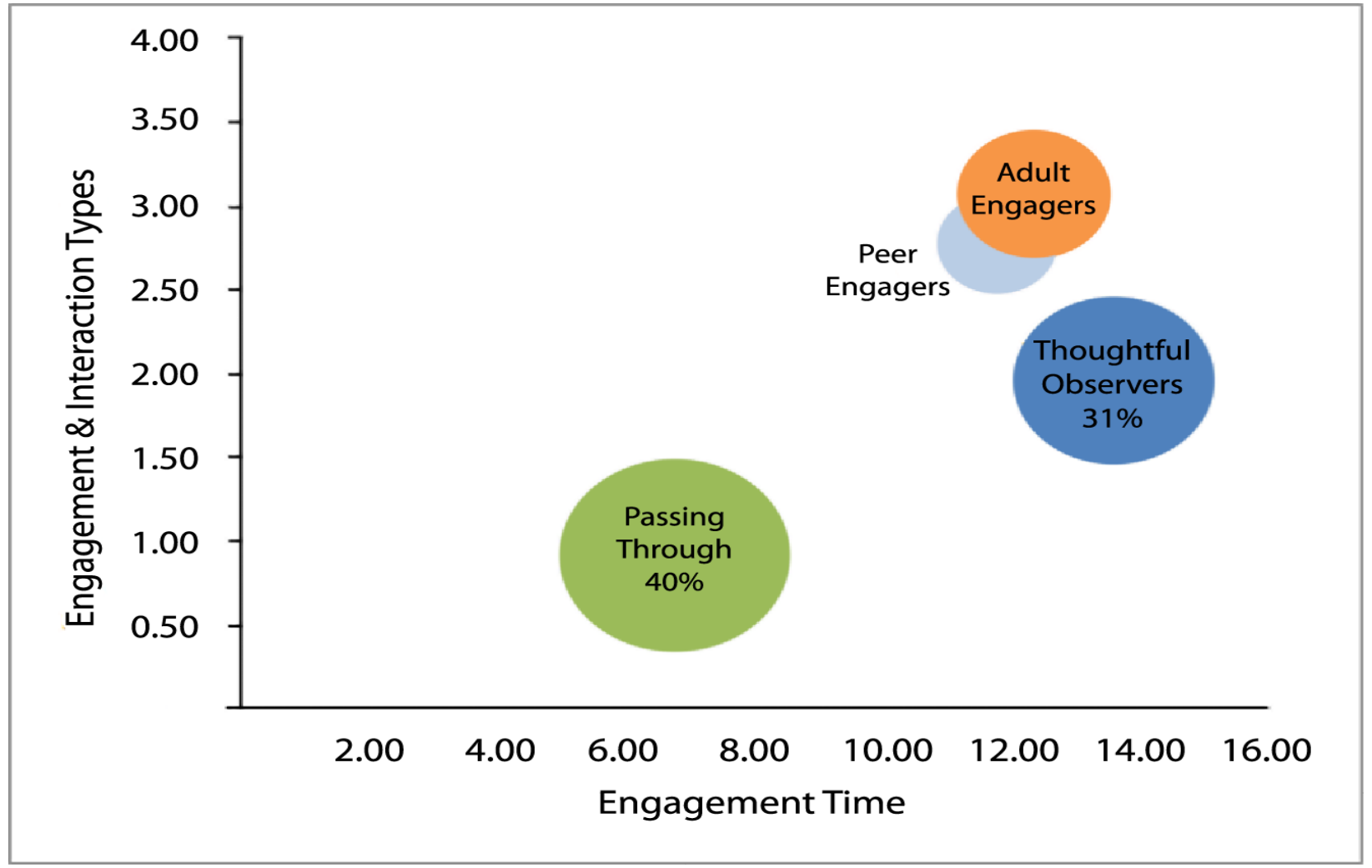

\section{Discussion}

Visitors to public science festivals have a tremendous amount of free choice in terms of deciding how to navigate through the festival (i.e., many possible routes), as well as when, where, and how long they choose to stop at an exhibit. The data collected for this study show that children are most likely to actively engage by doing and talking during earlier exhibit stops, followed by increasing amounts of time passively looking during subsequent exhibit stops.

Waiting was not a detrimental attribute of the exhibits; rather, the authors argue that a child's willingness to wait is an indicator of a high-value exhibit. Most children (95\%) were willing to wait briefly in order to engage with their first science activity. Among those exhibits where children were most likely to wait: 1) these exhibits were among the most visited by the observed children, 2) multiple children under observation were willing to wait at these same exhibits, and 3) a statistically significant relationship existed between the number of exhibit stops made and the number of stops where a child spent time waiting. Waiting did not diminish the children's enthusiasm to visit subsequent exhibit stops. As the large majority (87\%) of observed exhibit stops did not have wait times, children who waited at exhibit stops likely had the option to bypass these lines in favor of exhibits with no wait time but chose 
to wait and engage with these high-value exhibits. That said, we cannot ascertain whether the children choose to wait because they saw other children waiting, or whether their choice to was due to exhibit activity itself.

High levels of child interaction with their adult guardian influenced their experience, leading to longer periods of engagement. High levels of child interaction with peers also resulted in longer engagement times and resulted in a particular behavior pattern as highlighted through the cluster analysis. The analysis also revealed an unexpected pattern of engagement, in that children with above average interaction with their adult guardian also were inclined to interact with the adult exhibitors, while the children with high levels of peer interaction followed a slightly different pattern of engagement (see Figure 3).

However, the social engagers were not the only groups with above average levels of engagement. A group of children were observed engaging in a non-exhibit activity; these children had limited adult and peer interaction, but high engagement time with the festival's natural environment. They spent less time engaging with exhibits and more time engaging in unstructured play on the beach and watching the wildlife while their adult guardians observed. This data agrees with work done by Yoon, Lee \& Lee (2010) regarding the importance of physical surroundings of a festival, and the authors assert that ambient, non-programmatic festival elements are integral to the overall visitor experience, and should be considered fully during festival planning.

The authors speculate that visitor preference to engage in collaborative activities or independent free play may stem from a variety of factors, including learning styles, parenting approaches, or even the types of activities these children normally participate in. During data collection, the co-author observed anecdotally that some of the child subjects appeared to be guided to exhibits by their adult guardians. In one case, a child appeared to be coaxed to visit several exhibits by an adult guardian, who modeled positive interactions with each exhibitor until the child found an exhibit activity in which they were willing to engage. This leads to new questions about free choice learning and who exactly is making choices in the "free choice" science learning environment. Further research could observe and document family groups as they navigate such an environment, documenting who makes the choice for the group to visit a particular exhibit. This data would be extremely useful for festival organizers who have a strong interest in understanding how festival visitors make decisions about which exhibits to visit, and what types of exhibits appeal to that specific audience, so that they can advise exhibitors on how to build an effective exhibit.

\section{Conclusion}

Unobtrusive observation yields valuable insights into child engagement and interaction at public science festivals. The observational data support earlier research showing that children actively engage with festival exhibits, and the data analysis found that they engage with activities in multiple ways and with varying levels of engagement over time. Several factors influence child engagement in a free-choice learning environment, including attention capacity and goals (e.g. engage with exhibits, explore the ambient environment, eat lunch), the ability to interact with peers and adults during their engagement, and the ability to make choices about engaging in collaborative activities or independent free play. 
Further, the authors make the following recommendations for festival planning and operations:

- Exhibit wait times are not a negative indicator of an overly crowded festival, but may be an indication of a high-value exhibit;

- Exhibitors should be encouraged to develop exhibit activities with multiple options for independent and collaborative engagement in order to suit different learning styles;

- Non-programmatic aspects of a science festival, including ambient environment and natural features are integral aspects of the overall festival experience and should be considered as such during festival planning.

Although it was beyond the scope of this study, it also seems that the types of engagement observed here could be linked more explicitly to the science learning outcome set out by the National Research Council (2009) of inspiring excitement, curiosity, and motivation to learn about science, which are key goals of science festivals and other types of public science events. In addition, this study raised questions about free choice learning, and who makes the decision to visit science festivals, visit particular exhibits, and initiate engagement. Further investigation into child agency as they navigate the festival site would be useful in determining a target audience to which exhibit presentation and display should appeal for maximum effectiveness.

All subject groups (i.e., at least one child and accompanying adult guardian) observed during this study took full advantage of the free choice learning environment provided by the St. Petersburg Science Festival; each group had their own unique festival experience complete with unique routes, choices of exhibit stops, choices of engagement type and intensity, and choice of interaction levels with adults and/or peers. 


\section{Bibliography}

Barriault, C., \& Pearson, D. (2010). Assessing exhibits for learning in science centers: A practical tool. Visitor Studies, 13(1), 90-106. https://doi.org/10.1080/10645571003618824

Bitgood, S. (2006). An Analysis of Visitor Circulation: Movement Patterns and the General Value Principle. Curator: The Museum Journal, 49(4), 463-475. https://doi.org/10.1111/j.21516952.2006.tb00237.x

Borun, M., Chambers, M. B., Dritsas, J., \& Johnson, J. I. (1997). Enhancing Family Learning Through Exhibits. Curator: The Museum Journal, 40(4), 279-295. https://doi.org/10.1111/j.21516952.1997.tb01313.x

Braunsberger, K. (2016). Evaluation Report. St. Petersburg.

Braunsberger, K., Jakupaj, S., Dzien, D., \& Damian, J. (2017). Evaluation Report 2016. St. Petersburg.

Bultitude, K., McDonald, D., \& Custead, S. (2011). The Rise and Rise of Science Festivals: An international review of organised events to celebrate science. International Journal of Science Education, Part B, 1(2), 165-188. https://doi.org/10.1080/21548455.2011.588851

Durant, J., Buckley, N., Comerford, D., Fogg-Rogers, L., Fooshee, J., Lewenstein, B., \& Wiehe, B. (2016). Science Live: Surveying the landscape of live public science events, 46 . Retrieved from https://livescienceevents.files.wordpress.com/2016/02/2016-science-live-landscapesurvey.pdf\%5Cns

Falk, J. H. (2005). Free-choice environmental learning: framing the discussion. Environmental Education Research, 11(3), 265-280. https://doi.org/10.1080/13504620500081129

Falk, J. H., Donovan, E., \& Woods, R. (2001). Free-choice science education : how we learn science outside of school. Teachers College Press. Retrieved from http://eds.a.ebscohost.com/eds/command/detail?vid=2\&sid=5d866eef-3c51-4613-ba063f9d2f3835c6\%40sessionmgr4010\&bdata=JnNpdGU9ZWRzLWxpdmU\%3D\#AN=usflc.020088893\&d $\mathrm{b}=\mathrm{cat} 00847 \mathrm{a}$

Falk, J. H., \& Storksdieck, M. (2005). Using the Contextual Model of Learning to understand visitor learning from a science center exhibition. Science Education, 89(5), 744-778. https://doi.org/10.1002/sce.20078

Flipp, G. (2017). Cluster Analysis For Marketing. Retrieved March 16, 2018, from http://www.clusteranalysis4marketing.com/

Hornecker, E. (2008). "I don't understand it either, but it is cool" - Visitor Interactions with a Mult-Touch Table in a Museum. In 2008 IEEE International Workshop on Horizontal Interactive Human Computer System (TABLETOP)2 (pp. 113-120).

Jensen, E., \& Buckley, N. (2014). Why people attend science festivals: Interests, motivations and selfreported benefits of public engagement with research. Public Understanding of Science, 23(5), 557-573. https://doi.org/10.1177/0963662512458624

National Research Council. (2009). Learning Science in Informal Environments: People, Places, and Pursuits. (P. Bell, B. Lewenstein, A. Shouse, \& M. A. Feder, Eds.). Washington, D.C: The National Academies Press. Retrieved from 
https://books.google.com/books?hl=en\&lr=\&id=EzP737BHvrUC\&oi=fnd\&pg=PP1\&ots=7wbm7J8PK $R \&$ sig=49zwv7RxtDCV5vkFokYmv7Lt24A\#v=onepage \&q\&f=false

National Science Foundation. (2018). Merit Review Facts. Retrieved January 24, 2018, from https://www.nsf.gov/bfa/dias/policy/merit_review/facts.jsp\#1

Peterman, K., \& Gathings, M. J. (n.d.). Community-Created Multi-Site Evaluations: A Method to Promote Evaluation Use Across a Sector. American Journal of Evaluation.

Seaton, A. V. (1997). Unobtrusive Observational Measures as a Qualitative Extension of Visitor Surveys at Festivals and Events: Mass Observation Revisited. Journal of Travel Research, 35(4), 25-30. https://doi.org/10.1177/004728759703500414

St. Petersburg Science Festival. (2011). Mission. Retrieved January 23, 2018, from http://www.stpetescifest.org/?page=mission

Tal, T., \& Morag, O. (2007). School Visits to Natural History Museums: Teaching or Enriching? Journal of Research in Science Teaching, 44(5), 747-769. https://doi.org/10.1002/tea

van Beynen, K., Pettijohn, P., \& Carrel, M. (2010). Using pedestrian choice research to facilitate resource engagement in a midsized academic library. Journal of Academic Librarianship, 36(5), 412-419. https://doi.org/10.1016/j.acalib.2010.06.005

Wagoner, B. (2010). Science Learning at the Zoo: Evaluating Children's Developing Understanding of Animals and their Habitats. Psychology \& Society, 3(1), 65-76. https://doi.org/10.1017/CBO9781107415324.004

Wilkinson, C., \& Weitkamp, E. (2016). Impact. In Creative Research Communication: Theory \& Practice (pp. 205-234). Manchester: Manchester University Press.

Yoon, Y.-S., Lee, J.-S., \& Lee, C.-K. (2010). Measuring Festival Quality and Value Affecting Visitors' Satisfaction and Loyalty Using a Structural Approach. International Journal of Hospitality Management, 29(2), 335-342. 